Scientific Review - Engineering and Environmental Sciences (2021), 30 (1), 195-207

Sci. Rev. Eng. Env. Sci. (2021), 30 (1)

Przegląd Naukowy - Inżynieria i Kształtowanie Środowiska (2021), 30 (1), 195-207

Prz. Nauk. Inż. Kszt. Środ. (2021), 30 (1)

http://iks.pn.sggw.pl

DOI 10.22630/PNIKS.2021.30.1.17

Thaer O. ROOMI, Adel S. ABED

Mustansiriyah University, College of Science

\title{
Estimating gaseous pollutants in the air near Daura Refinery, Daura Power Plant and South of Baghdad Power Plant by calculating the fuel discharge
}

Key words: gaseous pollutants, $\mathrm{SO}_{2}, \mathrm{CO}, \mathrm{NO}_{2}$, power plant, refinery

\section{Introduction}

Air is polluted when there are odd substances in it, and these substances become undesirable when their presence in a concentration may cause great harm to humans, their properties and their environment. These odd materials (pollutants) may be in the form of aerosols or gases (Vallero, 2014). The environmental pollution caused by the industrial facilities has become a global concern. Part of the complexity of this problem is the conflict between the economic benefits of these facilities and their risks to public health and the surrounding environment (Al-Jahdali \& Bin Bisher, 2008). The industrial facilities emits several atmospheric pollutants including $\mathrm{SO}_{2}$, $\mathrm{H}_{2} \mathrm{~S}, \mathrm{NO}_{\mathrm{X}}, \mathrm{CO}$, hydrocarbons and other poisonous materials (Damian, 2014).
Many diseases such as cancer, heart disease, pneumonia and premature death can occur because of exposure to gases from refineries, power plants and other industrial facilities (Shubbar, 2019). Sulfur dioxide gas dissolves rapidly in atmospheric water vapor, thus acid rain builds up in air, soil and plants around refineries and power plants (Zhao, Li, Xiao \& Li, 2019). This gas caused primarily by refineries and power plants (Liu, Yang, Zhang Xiang \& Wei, 2019). Many research works confirmed that $\mathrm{NO}_{2}$ has serious problems to humans and contributing in agriculture degrading by affection on the chlorophyll (Camargo \& Lombardi, 2018; Sheng \& Zhu, 2019). Carbon monoxide resulting from incomplete combustion of carbon materials. It affects human health and plants due to its toxic nature (Cuinica, Abreu, Gomes \& Esteves da Silva, 2013). One of the important factors in the dispersion and transmission of pollutants is the air stability. On diurnal to sub-diur- 
nal timescales, variation in air stability can cause a comparable or greater influence on the variability of urban pollutant concentrations than the changes in source emission or advection (Wang et al., 2016). Wind speed and direction patterns plays an important role in dispersion and mitigation of the high concentration of gas pollutants. However, they distribute the pollutions to cover more remote regions (Manii \& Al-Jumaylii, 2012). Many research works address the pollution problem and the environmental effects of refineries and power plants in Iraq. Al-Suhaili and Al-Khafaji (2015) built a mathematical model for integrated air pollution modelling around refineries and took Daura Refinery as a study case. The model demonstrates the influence of atmospheric stability, wind speed, emission rate, exit velocity, physical height, exit temperature and rural-urban area in reducing the concentrations of pollutants. Al-Dabbas, Ali and Afaj (2012) studied the concentrations of pollutants around Kirkuk Refinery by using low volume air sampler (a sniffer) in 2010 and 2011. The results revealed that the concentrations were higher than the permissible limits of the Iraqi national determinants. Al-Hassen, Al-Qarooni, Qassim, Al-Saad and Alhello (2015) determined the gaseous pollutants concentrations of $\mathrm{CO}, \mathrm{NO}_{2}$, and $\mathrm{SO}_{2}$ emitted from selected emission sources at Basra city. The results revealed that the concentrations of the above pollutants exceeded the maximum permissible limits for Iraqi National Emission Standards. Shubbar, Suadi and Al-Jiboori (2018) studied the dispersion of $\mathrm{SO}_{2}$ from Daura Refinery by using ScreenView model and checked the effect of the wind speed and direction on the spread of pollutants. The three pollutants $\left(\mathrm{CO}, \mathrm{SO}_{2}\right.$ and $\left.\mathrm{NO}_{2}\right)$ have been also taken up by researchers from around the world. García-Gusano, Cabal and Lechón (2015) carried out a study to ease the lack of National Emission Ceilings (NEC) Directive assessments at country level for Spain. The amount of $\mathrm{NOx}$ and $\mathrm{SO}_{2}$ emissions were analyzed using the TIMES-Spain energy optimization model. Abiye et al. (2016) provided model-based estimates of atmospheric dispersion for gaseous pollutants $\left(\mathrm{SO}_{2}\right.$ and $\mathrm{NO}_{\mathrm{X}}$ ) released from a scrap-iron recycling factory located in southwest of Nigeria. The study identified the pollutant concentrations increase by stable atmosphere, weak wind speed, low mixing height, and high relative humidity. A comprehensive Canadian study conducted by Ragothaman and Anderson (2017) presented a review of findings from different studies on air quality impacts of petroleum refining and petrochemical plants in several cities around the world. Kumar, Bhushan and Kishore (2018) applied a dispersion modeling approach to determine $\mathrm{SO}_{2}$ and $\mathrm{NO}_{2}$ concentrations in the surrounding air of the industrial and mining cluster in Keonjhar, India for one year 2015. Filonchyk, Hurynovich, Yan, Gusev and Shpilevskaya (2020) carried out a study focused on East China and attempted to assess comprehensively the environmental impact of the COVID-19 disease 2019 outbreak. The study analyzed satellite images of $\mathrm{SO}_{2}, \mathrm{NO}_{2}, \mathrm{CO}$ and aerosol optical depth in the period before and during the outbreak of the epidemic. The data then was compared with the data before the epidemic in 2019. The results showed that the COVID-19 lockdown improved air 
quality in the short term, but as soon as power plants and refineries came back to normal work, pollution levels returned to their previous level.

In this study, the emitted pollutants of $\mathrm{CO}, \mathrm{SO}_{2}$ and $\mathrm{NO}_{2}$ emerged from each of Daura Refinery (DR), South of Baghdad Power Plant (SBPP) and Daura Power Plant (DPP) was addressed. These three facilities uses the crude oil and are situated in a region of less than $3 \mathrm{~km}$ in diameter. Two of them (DR and BSPP) was established in 1950s, while DPP was established in 1981. In 1950s, these facilities where outside the city and no houses in around (Murtadah, Al-Sharify \& Hasan, 2020). However, nowadays, these facilities are surrounded by inhabited cities, which are affected by the pollution of undesired gases. Therefore, the Iraqi committee of health and environment in the Iraqi parliament called for a decision to transfer DR to another place according to environmental and international regulations (Murtadah et al., 2020). However, due to the economic difficulties the country is going through, this option is no longer on the table now.

\section{Gaussian plume model of dispersion}

Gaussian dispersion models are extensively used to calculate local pollution levels. The accuracy of such models depends on stability determination (Awasthi, Khare \& Gargava, 2006). This model utilizes an emissions rates, meteorological elements, and equations, which describe mathematically the physical process of turbulent transport of air pollutants in the boundary layer to calculate concentrations. Gaussian plume equation tells mathematically how to compute the concentration of a gas or any comparable in size, solid or liquid pollutant being emitted continuously from a single source (Weber, 1982), the equation can be written simply by (Leelössy et al., 2014):

$$
\begin{aligned}
& C(X, Y, Z, H)=\frac{Q}{2 \pi \sigma_{y} \sigma_{z} U} \exp \left[-\frac{1}{2}\left(\frac{y}{\sigma_{y}}\right)^{2}\right]\left[\exp \left(-\frac{1}{2}\left(\frac{z-H}{\sigma_{z}}\right)^{2}\right)+\right. \\
& \left.+\exp \left(-\frac{1}{2}\left(\frac{z+H}{\sigma_{z}}\right)^{2}\right)\right]
\end{aligned}
$$

where:

$C$ - concentration [ppm of $\mathrm{kg}$ ],

$X$ - horizontal distance in downwind direction $[\mathrm{m}]$,

$Y$ - central line of pollutants dispersion $[\mathrm{m}]$,

$Z$ - vertical altitude above surface $[\mathrm{m}]$,

$H$ - effective height of chimney $(H=h+$

$+\Delta h$, in which $h$ is chimney height and $\Delta h$ is plume height) [m],

$Q$ - emission rate $\left[\mathrm{kg} \cdot \mathrm{s}^{-1}\right]$,

$\sigma_{y}, \sigma_{z}-$ Gaussian plume standard deviations in horizontal (crosswind) and vertical directions,

$U$ - wind speed at the effective height of chimney $\left[\mathrm{m} \cdot \mathrm{s}^{-1}\right]$.

Our current study estimated the concentrations of by using the consumed fuel in three facilities: Daura Refinery (DR), Daura Power Plant (DPP) and South of Baghdad Power Plant (SBPP). The calculation implemented by using Gaussian dispersion model. The effects of the stability, wind speed and direction, chimneys height and diameter were also investigated. The most affected cities were determined, as well. 


\section{Material and methods}

\section{Location}

Daura Refinery, Daura Power Plant are located in Daura District, south of Baghdad, while South of Baghdad Power Plant is located to the east of the refinery, $2 \mathrm{~km}$ away on the other side of the Tigris river. The area surrounding these facilities is urban areas of flat nature devoid of complex terrain as well as of tall buildings (Fig. 1). on SBPP was obtained from the power plant. Data about DPP was obtained from the Environment Unit in the Department of Planning and Studies, Iraqi Ministry of Electricity. The meteorological data of $10 \mathrm{~m}$ wind speed and hourly $1.5 \mathrm{~m}$ air temperatures of year 2017 of Daura District were obtained from the European Center for Medium Weather Forecast (ECMWF) website. DR contains 12 units that have 35 chimneys, DPP has four units connected to four chimneys, while SBPP

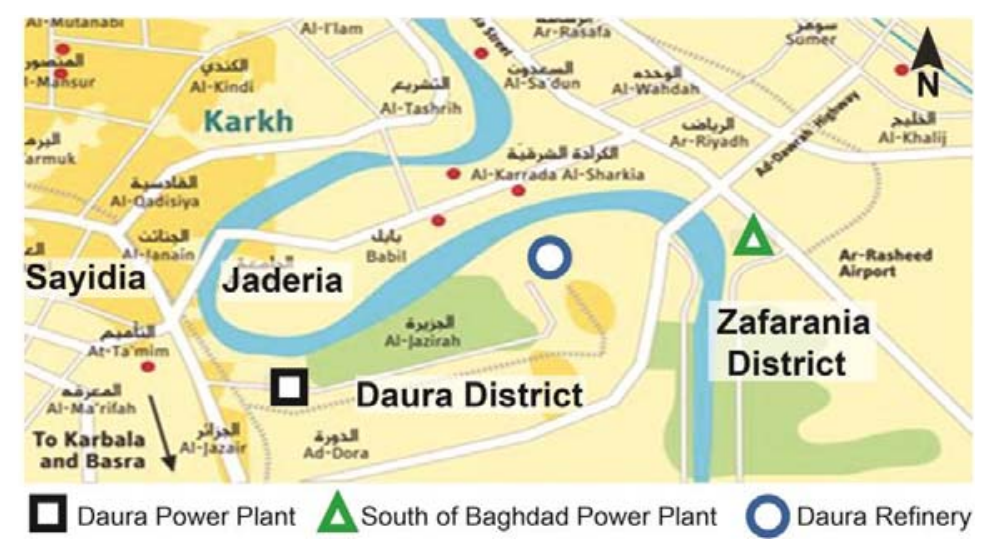

FIGURE 1. Location of examined emitters of air pollution

\section{Data}

The data were used for the monthly quantities of fuel discharged in each unit of DR for year 2017, and the data for the height, diameter, and temperature of the outgoing gas were used. These data were obtained from DR. Likewise, the data has six units, three of which only are in operation, and each of the plant's units is connected to one chimney. To consider these units as a single point source, the height and diameter of the chimney and the temperature of the gas exiting from it were calculated as rates. Table 1 lists the information of the chimneys.

TABLE 1. Chimney characteristics of the pollutions sources

\begin{tabular}{|l|c|c|c|}
\hline Specification & $\begin{array}{c}\text { Daura Refinery } \\
\text { (DR) }\end{array}$ & $\begin{array}{c}\text { South of Baghdad } \\
\text { Power Plant } \\
\text { (SBPP) }\end{array}$ & $\begin{array}{c}\text { Daura Power Plant } \\
\text { (DPP) }\end{array}$ \\
\hline Chimney average height $[\mathrm{m}]$ & 29 & 54 & 100 \\
\hline Chimney average diameter $[\mathrm{m}]$ & 1.5 & 2 & 2.5 \\
\hline Chimney exit gas temperature $[\mathrm{K}]$ & 615 & 460 & 433 \\
\hline
\end{tabular}




\section{Concentrations of $\mathrm{SO}_{2}, \mathrm{CO}$ and $\mathrm{NO}_{2}$}

Concentrations of $\mathrm{SO}_{2}, \mathrm{CO}$ and $\mathrm{NO}_{2}$ gases emitted from DR, DPP and SBPP were calculated for four months representing the seasons of 2017 (January, April, July and October) for a distance of $10 \mathrm{~km}$ from the source. The concentrations were calculated by using Gaussian plume model of dispersion, which requires gas emission rate, chimney's gas exit velocity in addition to the height, diameter, and gas exit temperature of the chimney. The method uses the data of consumed fuel. To calculate gas emission rates, the monthly fuel quantities data converted into hourly rates and then to convert volume units to mass units. Calculation of emission rates and gas exit velocity were computed by FORTRAN script.

\section{Effect of stability and wind on pollutants concentrations}

The concentrations were calculated for slightly stable (E) and moderately unstable air classes (B) for four months in 2017: January, April, July, October. Finally, a comparison among the three sources (DR, DPP, SBPP) of the emission rates and concentrations of pollutants was made to quantify the contribution of each source of the three pollutant gases $\left(\mathrm{SO}_{2}, \mathrm{CO}, \mathrm{NO}_{2}\right)$.

\section{Results and discussion}

\section{Emission rates}

The results of emission rates and gas exit speed were shown in Table 2. It is clear that DPP consumed more fuel and emitted more pollutants than the other sources.

TABLE 2. Emission rates and gas exit speed of Daura Refinery (DR), South of Baghdad Power Plant (SBPP) and Daura Power Plant (DPP)

\begin{tabular}{|l|c|c|c|c|c|}
\hline Specification & Facility & January & April & July & October \\
\hline \multirow{3}{*}{ Consumed fuel mass $\left[\mathrm{kg} \cdot \mathrm{h}^{-1}\right]$} & DR & 41428 & 45056 & 51997 & 47964 \\
\cline { 2 - 6 } & SBPP & 25629 & 24189 & 25164 & 20680 \\
\cline { 2 - 6 } & DPP & 57980 & 77184 & 94321 & 64505 \\
\hline \multirow{3}{*}{$\mathrm{SO}_{2}$ emission rate $\left[\mathrm{g} \cdot \mathrm{s}^{-1}\right]$} & DR & 904 & 1037 & 1123 & 1017 \\
\cline { 2 - 6 } & SBPP & 598 & 564 & 587 & 482 \\
\cline { 2 - 6 } & DPP & 1352 & 1800 & 2200 & 1505 \\
\hline \multirow{3}{*}{$\mathrm{CO}$ emission rate $\left[\mathrm{g} \cdot \mathrm{s}^{-1}\right]$} & DR & 862 & 863 & 1023 & 930 \\
\cline { 2 - 6 } & SBPP & 660 & 623 & 648 & 533 \\
\cline { 2 - 6 } & DPP & 1495 & 1990 & 2432 & 1663 \\
\hline \multirow{3}{*}{$\mathrm{NO}_{2}$ emission rate $\left[\mathrm{g} \cdot \mathrm{s}^{-1}\right]$} & DR & 84 & 89 & 97 & 84 \\
\cline { 2 - 6 } & SBPP & 61 & 58 & 60 & 49 \\
\cline { 2 - 6 } & DPP & 139 & 185 & 226 & 154 \\
\hline \multirow{3}{*}{$\mathrm{Gas}^{-1}$ exit speed $\left[\mathrm{m} \cdot \mathrm{s}^{-1}\right]$} & DR & 5.5 & 6.1 & 7.2 & 6.9 \\
\cline { 2 - 6 } & SBPP & 18.8 & 17.7 & 18.4 & 15 \\
\cline { 2 - 6 } & DPP & 19.3 & 25.7 & 31.4 & 21.5 \\
\hline
\end{tabular}




\section{Concentrations of the pollutants at four months of slightly stable condition (E)}

Figure 2 shows the pollutant concentrations emitted from DR for the four months when the atmosphere is slightly stable (E). The figures showed that the pollutant concentrations change with distance, as the pollutants concentrations at the surface level increase in the beginning with moving away from the point source and then decrease after that. It was observed that the highest concentration of pollutants is approximately at distance of $1,000 \mathrm{~m}$. This high value can be justified due to the fact that the gas leaving the chimney is at a higher temperature than the surrounding temperature and therefore its density is lower than the surroundings' density. The gas rises higher due to the force of buoyancy and turbulence enhancing pollutants dispersion and reducing the concentrations. With increasing distance from
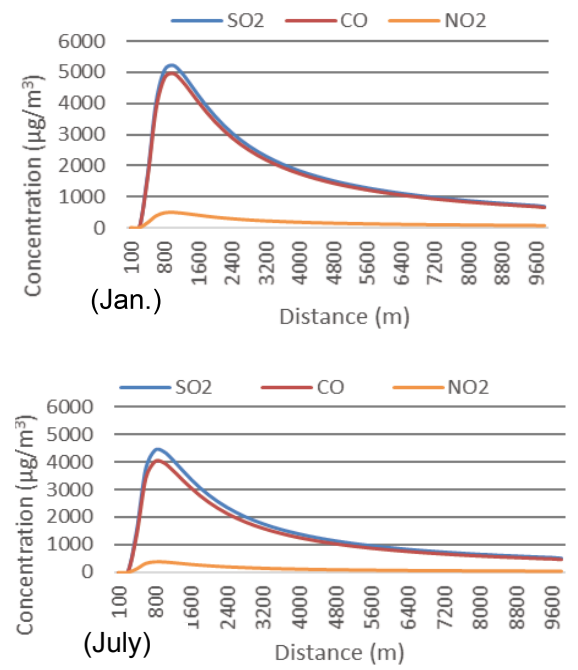

the source, the plume mixes with the surrounding air. The temperature decreases gradually and the buoyancy force will be diminished and the vertical movement will be inhibited. Therefore, the concentrations of pollutants increase gradually in the distance less than $1,000 \mathrm{~m}$. After this distance, pollutants concentrations begin to decrease gradually due to their departure from the source. Although the lowest emission rates of pollutants were during January, concentrations of pollutants at the surface level were the highest during this month. This may due to the lower wind speed in addition to the stratification of stable weather and inversion during this month. It was also noted that the concentration of $\mathrm{SO}_{2}$ is slightly higher than $\mathrm{CO}$ and that the ratio of $\mathrm{SO}_{2}$ to $\mathrm{CO}$ is greater in April. This may be due to the fact that the consumption of gaseous fuel is greater than that of liquid fuels in April when the need to electricity is the lowest. It is well known that the gaseous fuel releases more quantities of
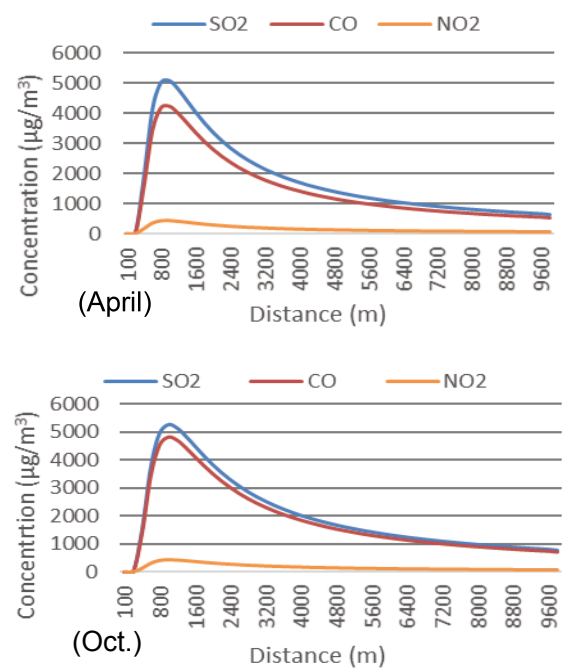

FIGURE 2. Pollutants concentration at stable conditions, at Daura Refinery 
$\mathrm{SO}_{2}$ than $\mathrm{CO}$. On the other hand, it was observed that the concentrations of $\mathrm{NO}_{2}$ gas was fewer compared to $\mathrm{SO}_{2}$ and $\mathrm{CO}$. This low value of $\mathrm{NO}_{2}$ is normal for refineries (Nirel \& Dayan, 2001).

Figure 3 shows the concentrations of pollutants emitted from SBPP at slightly stable condition (E). The highest concentration of pollutants was during January which might due mainly to the high quantities of fuel consumed during this month. Also, the wind speed during January was the least leading to an increase in concentrations. It was also observed that the concentration of $\mathrm{CO}$ was slightly higher than $\mathrm{SO}_{2}$, while the concentrations of $\mathrm{NO}_{2}$ were lowest.

Figure 4 shows the concentrations of pollutants emitted from DPP in a slightly stable weather condition. It was observed that the highest concentration of pollutants was during November, and the lowest was during January and July. Although the wind speed during July is higher than January, the emission rates of pollutants during July were also high and the values were close to January.

\section{Moderately unstable condition (B)}

Figure 5 shows the pollutant concentrations emitted from DR in moderately unstable condition (B). The highest concentration was approximately at distance of $200 \mathrm{~m}$ and then decreased greatly with the increase in the distance because the vertical movement was active, which led to mixing and dispersing of the pollutants, and thus the pollutant concentrations decreased. Hence, the pollutants concentration in this unstable condition was greater than in the case of moderately unstable atmosphere and with same wind speed.

In Figure 6, the dispersion of pollutants for SBPP at unstable conditions was very large and the concentrations were at their highest values at distances close
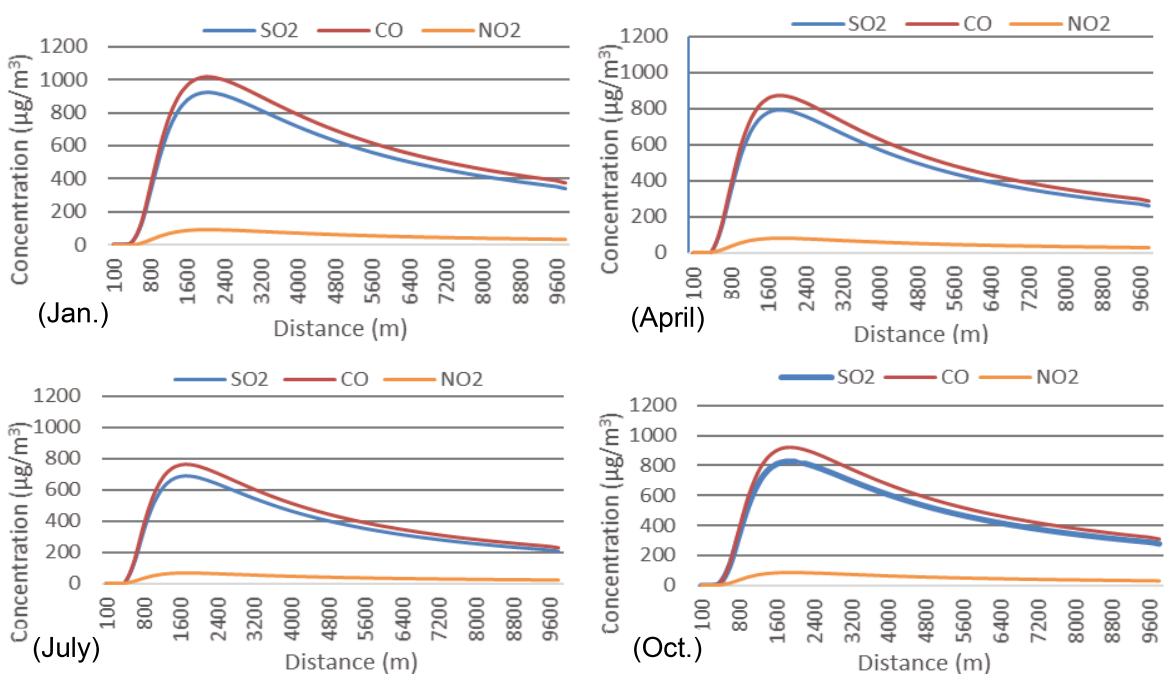

FIGURE 3. Pollutants concentration versus distance at stable conditions, at South of Baghdad Power Plant 

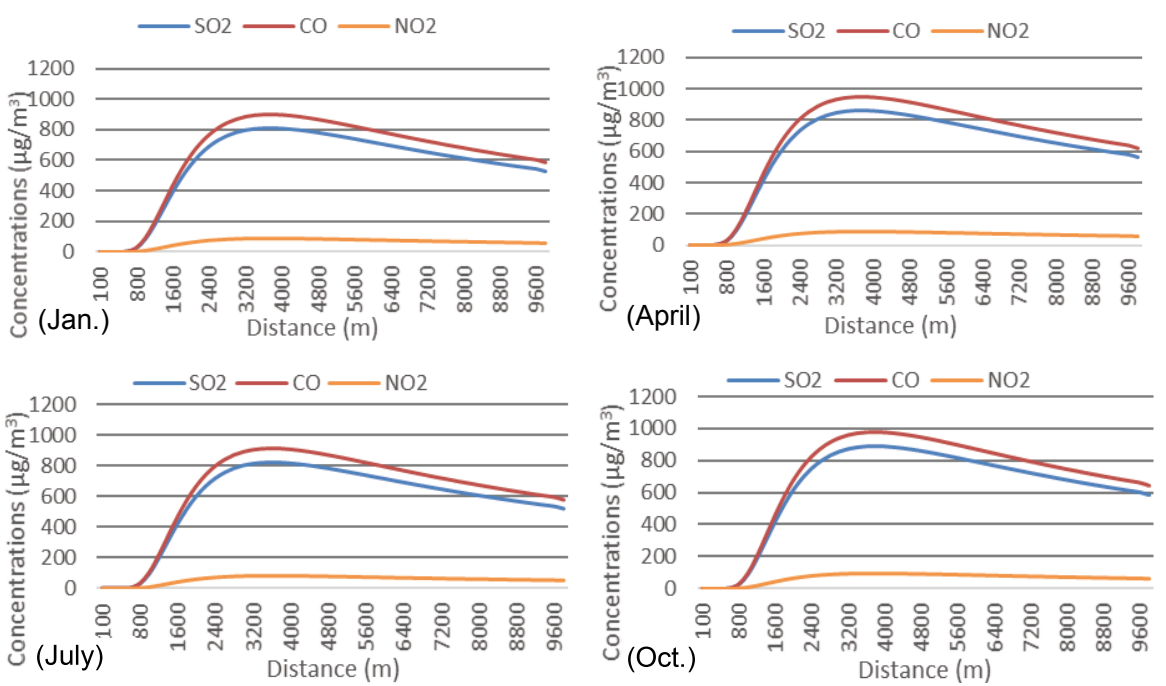

FIGURE 4. Pollutants concentration versus distance at stable conditions, at Daura Power Plant
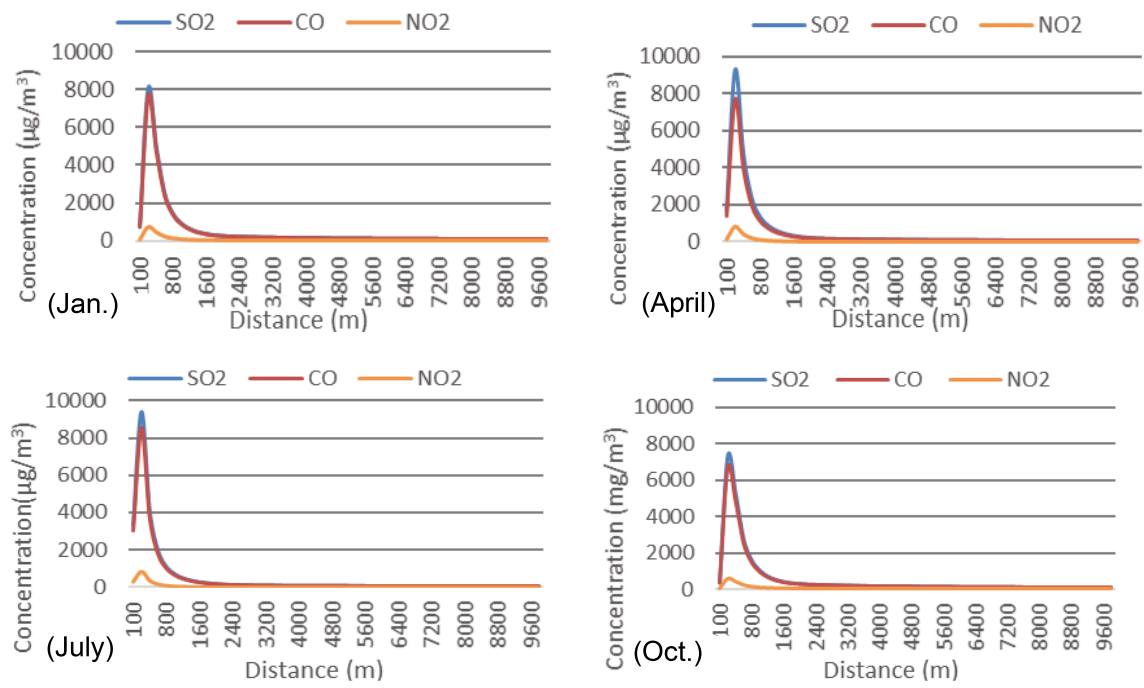

FIGURE 5. Pollutants concentration versus distance at unstable conditions, at Daura Refinery

to the plant. The highest concentration was approximately at $600 \mathrm{~m}$. The concentration then decreases gradually with increasing distance.

Figure 7 shows that the dispersion of pollutants in unstable conditions is very large for DPP, where the concentrations are at their highest values at distances close to the plant. The highest concentration was approximately at distance of $700 \mathrm{~m}$, then the concentration decreases with increasing distance. 

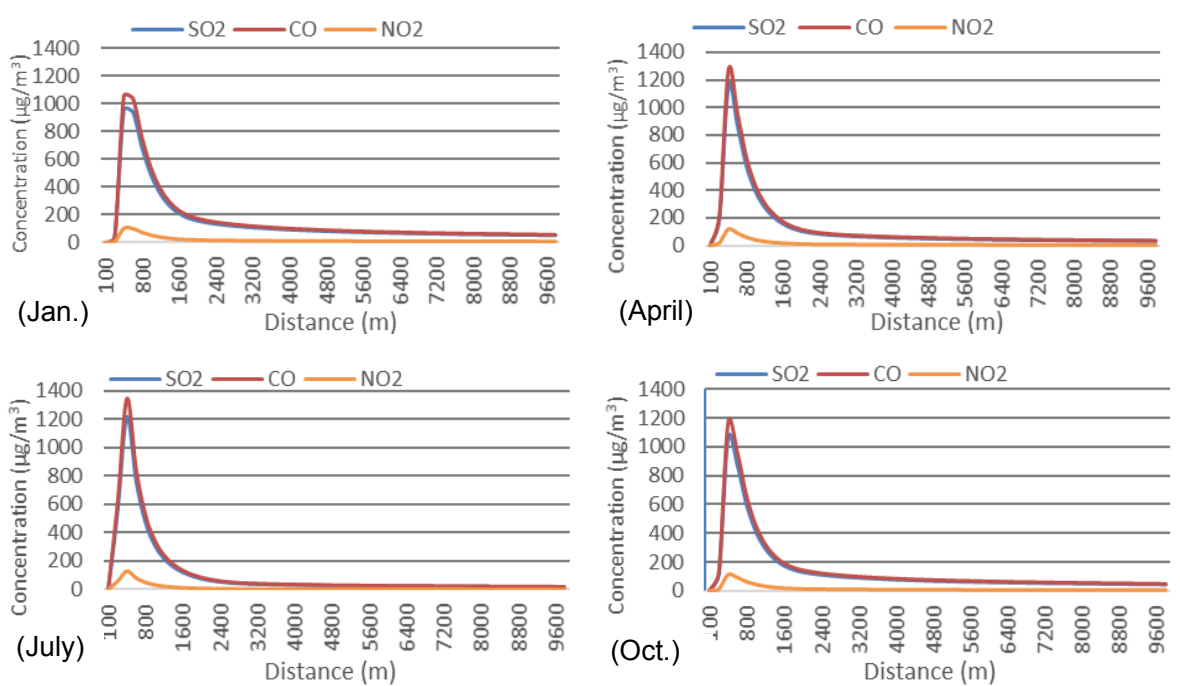

FIGURE 6. Pollutants concentration versus distance at unstable conditions, at South of Baghdad Power Plant
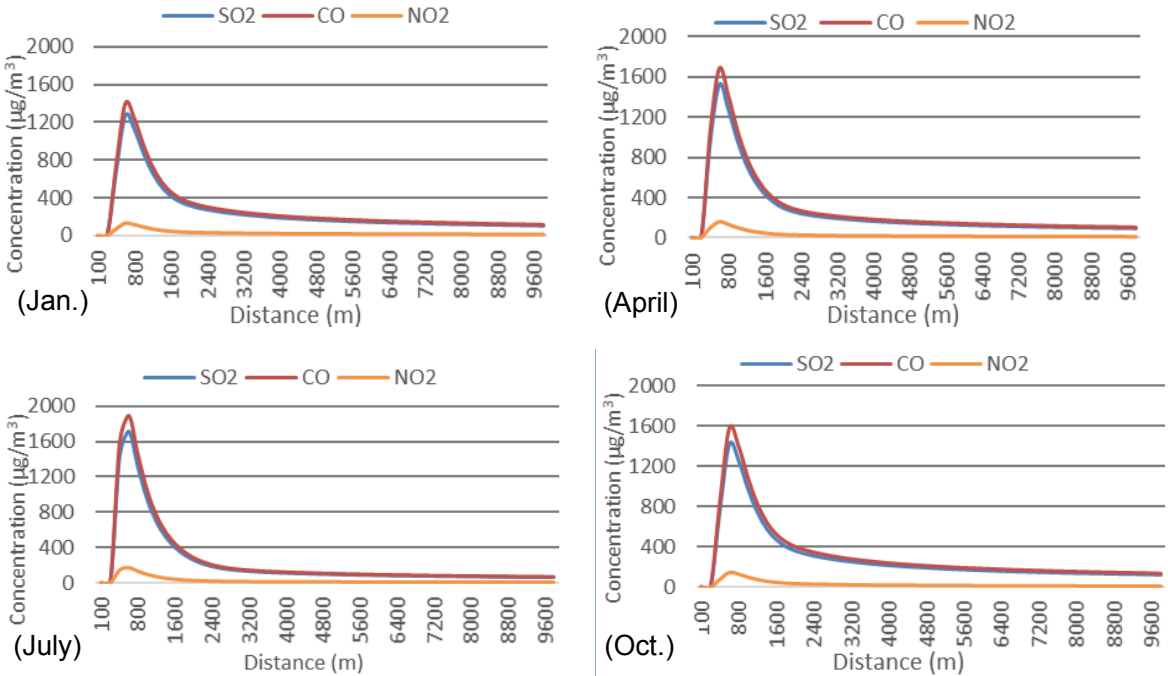

FIGURE 7. Pollutants concentration versus distance at unstable conditions, at Daura Power Plant

\section{Wind direction impact on pollutants dispersion}

Table 3 shows that the prevailing wind is northwest. In stable conditions, high pollutants concentrations can reach greater distances than in unstable conditions since they maintain near the ground. During January and July, Daura District was the most affected by DPP, while Zafarania District was the most affected by DR and SBPP because it was affected by northwest winds. Dur- 
TABLE 3. Prevailing wind in the study area for January, April, July, and October 2017

\begin{tabular}{|c|c|c|c|c|c|c|c|c|c|}
\hline \multirow{2}{*}{ Month } & \multirow{2}{*}{$\begin{array}{c}\text { Wind speed } \\
{\left[\mathrm{m} \cdot \mathrm{s}^{-1}\right]}\end{array}$} & \multicolumn{8}{|c|}{ Direction } \\
\hline & & $\mathrm{N}$ & $\mathrm{NE}$ & $E$ & SE & $\mathrm{S}$ & SW & $\mathrm{W}$ & NW \\
\hline \multirow{2}{*}{ January } & $0-5$ & 28 & 9 & 11 & 20 & 7 & 7 & 16 & 135 \\
\hline & $6-10$ & 0 & 0 & 0 & 6 & 0 & 3 & 1 & 5 \\
\hline \multirow{2}{*}{ April } & $0-5$ & 72 & 17 & 11 & 10 & 5 & 6 & 11 & 70 \\
\hline & $6-10$ & 6 & 2 & 3 & 4 & 3 & 0 & 1 & 20 \\
\hline \multirow{2}{*}{ July } & $0-5$ & 25 & 4 & 0 & 0 & 5 & 6 & 16 & 70 \\
\hline & $6-10$ & 18 & 0 & 0 & 0 & 0 & 0 & 2 & 103 \\
\hline \multirow{2}{*}{ October } & $0-5$ & 53 & 37 & 30 & 31 & 5 & 4 & 10 & 66 \\
\hline & $6-10$ & 0 & 0 & 0 & 6 & 4 & 0 & 0 & 3 \\
\hline
\end{tabular}

ing April, one can notice that along with the northwest winds, there were eastern winds that contribute to the transfer of pollutants emitted from DR and SBPP to Daura area, while Sayidia area was more affected by DPP. October had the most variable wind direction.

\section{Comparison of the three sources}

The emission rates and concentrations of pollutants emitted from DR, DPP and SBPP were visualized to make a comparison among them (Fig. 8). It is clear that the pollutants concentrations
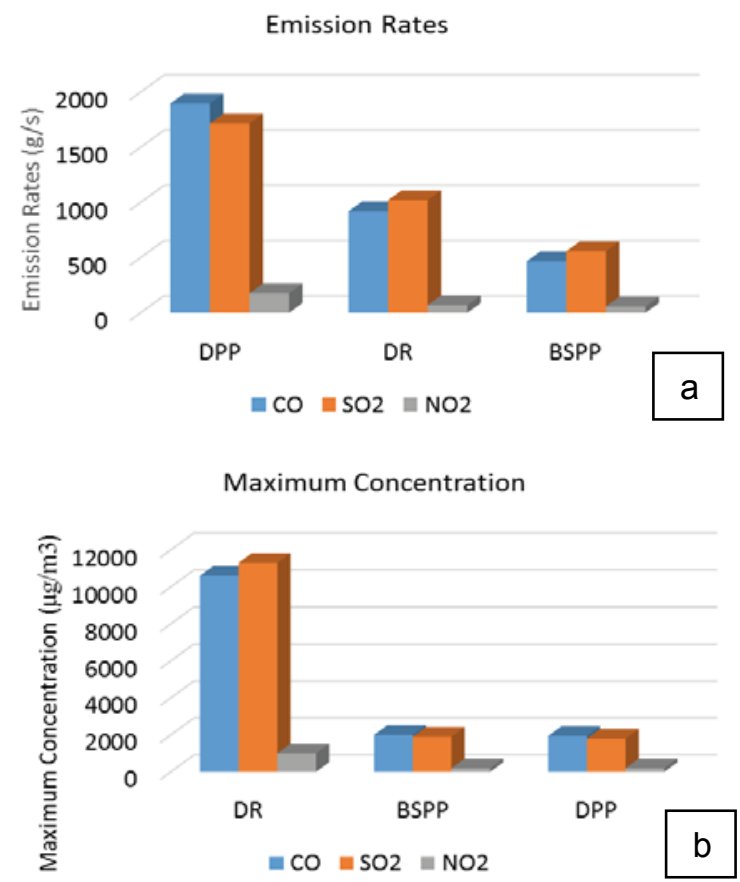

FIGURE 8. Facilities (a) emission rates and (b) maximum concentration 
emitted from DR at the ground level are greater than those emitted from DPP. This may due to the difference in effective plume height, as the greater the effective height of the plume, the greater the dispersion of pollutants. This give indication that this facility has serious problems on the human health and even the plants. The height of the chimney, the gas exit velocity, and the gas temperature lead to an increase in the effective height of the plume. Considering the diameter, the larger the diameter, the faster the gas leaving the chimney, the lower effective height of plume. Because of the high altitude of DPP chimneys, the wind speed is greater at the top causing greater reduction of pollutants. The high altitude of the chimney does not mean it is environmentally friendly because pollutants will just spread for longer distances. In these three sources, it was observed that the effect of the height of the chimney as well as the velocity of the gas leaving the chimney were more clear on the dispersion of pollutants than the effect of diameter and the temperature of the gas leaving the chimney.

\section{Conclusions}

1. The concentrations of pollutants in DR, BSPP and DRR increase in stable conditions due to the less air turbulence. Hence, the unstable atmospheres are better at dispersing pollutants.

2. Since the prevailing wind direction is northwest, Zafarania District is the most affected by the pollutants emitted from DR and BSPP while Daura District is very affected by DPP.
3. Wind speed has a clear effect on the dispersion of pollutants, the higher wind speed, the lower pollutant concentrations.

4. Pollutantconcentrationsincreasewith increasing emission rates and chimney diameter, and decreasing with increasing chimney height, speed of the gas leaving the chimney.

5. DPP has higher emission rates than DR and SBPP. However, at the surface level, the concentrations emitted from DR are greater than those emitted from DPP and SBPP. Thus, DR is the most affecting source on the health of people in the areas surrounding the refinery.

6. Although increasing the height of the chimney contributes to reducing the concentrations of pollutants at the surface level that does not mean it is environmentally friendly because pollutants will just spread for longer distances.

\section{Acknowledgements}

We acknowledge the Mustansiriyah University for offering all the facilities to complete this work. Also, we appreciate the European Centre for Medium-Range Weather Forecasts (ECMWF) for its important dataset. Also we thank the Ministry of Electricity and the Ministry of Oil for offering the data of consumed oil and the chimneys features.

\section{References}

Abiye, O., Sunmonu, L., Ajao, A., Akinola, O., Ayoola, M. \& Jegede, O. (2016). Atmospheric dispersion modeling of uncontrolled gaseous pollutants $\left(\mathrm{SO}_{2}\right.$ and $\left.\mathrm{NO}_{\mathrm{X}}\right)$ emission 
from a scrap-iron recycling factory in Ile-Ife, Southwest Nigeria. Cogent Environmental Sciences, 2(1). 1275413. https://www.doi. org/10.1080/23311843.2016.1275413

Al-Dabbas, M.A., Ali, L.A. \& Afaj, A.H. (2012). The effect of Kirkuk Oil Refinery on Air pollution of Kirkuk City-Iraq. Proceeding of the 1st Conference on Dust Storms and their Environmental Effects, 17(18), 8-18.

Al-Hassen, S.I., Al-Qarooni, E.H., Qassim M.H., Al-Saad, H.T. \& Alhello, A. (2015). An experimental study on the determination of air pollutant concentrations released from selected outdoor gaseous emission in Basra City, Southern Iraq. Journal of International Academic Research for Multidisciplinary, 3(1), 88-98.

Al-Jahdali, M.O. \& Bin Bisher, A.S. (2008). Sulfur dioxide $\left(\mathrm{SO}_{2}\right)$ accumulation in soil and plant's leaves around an oil refinery: A case study from Saudi Arabia. American Journal of Environmental Sciences, 4(1), 84-88.

Al-Suhaili, R.H. \& Al-Khafaji, M.S. (2015). Integrated system for air pollution around refineries. Journal of Engineering, 15(4), 4204-4218.

Awasthi, S., Khare, M. \& Gargava, P. (2006). General plume dispersion model (GPDM) for point source emission. Environmental Modeling and Assessment, 11(3), 267-276.

Camargo, E.C. \& Lombardi, A.T. (2018). Effect of cement industry flue gas simulation on the physiology and photosynthetic performance of Chlorella sorokiniana. Journal of Applied Phycology, 30(2), 861-871.

Cuinica, L.G., Abreu, I., Gomes, C.R. \& Esteves da Silva, J.C.G. (2013). Exposure of Betula pendula Roth pollen to atmospheric pollutants $\mathrm{CO}, \mathrm{O}_{3}$ and $\mathrm{SO}_{2}$. Grana, 52(4), 299-304.

Damian, C. (2014). Environmental pollution in the petroleum refining industry. Analele Universitatii "Ovidius" Constanta. Chimie, 24(2), 109-114.

Filonchyk, M., Hurynovich, V., Yan, H., Gusev, A. \& Shpilevskaya, N. (2020). Impact assessment of COVID-19 on variations of $\mathrm{SO}_{2}$, $\mathrm{NO}_{2}$, co and AOD over east China. Aerosol and Air Quality Research, 20(7), 1530-1540.

García-Gusano, D., Cabal, H. \& Lechón, Y. (2015). Evolution of $\mathrm{NO}_{\mathrm{x}}$ and $\mathrm{SO}_{2}$ emissions in Spain: Ceilings versus taxes. Clean Technologies and Environmental Policy, 17(7), 1997-2011.

Kumar, D.S., Bhushan, S.H. \& Kishore, D.A. (2018). Atmospheric dispersion model to predict the impact of gaseous pollutant in an industrial and mining cluster. Global Journal of Environmental Science and Management, 4(3), 351-358.

Leelőssy, Á., Molnár, F., Izsák, F., Havasi, Á., Lagzi, I. \& Mészáros, R. (2014). Dispersion modeling of air pollutants in the atmosphere: a review. Central European Journal of Geosciences, 6(3), 257-278.

Liu, Z., Yang, J., Zhang, J., Xiang, H. \& Wei, H. (2019). A bibliometric analysis of research on acid rain. Sustainability, 11(11), 3077. https://www.doi.org/10.3390/su11113077

Manii, J.K. \& Al-Jumaylii, A.K. (2012). Monthly variation of some air pollutants in Hilla City - middle of Iraq. Journal of University of Babylon, 22(1), 1-12.

Murtadah, I., Al-Sharify, Z.T. \& Hasan, M.B. (2020). Atmospheric concentration saturated and aromatic hydrocarbons around Dura refinery. IOP Conference Series: Materials Science and Engineering, 870(1), 012033. https://www.doi.org/10.1088/1757899X/870/1/012033

Nirel, R. \& Dayan, U. (2001). On the ratio of sulfur dioxide to nitrogen oxides as an indicator of air pollution sources. Journal of Applied Meteorology, 40(7), 1209-1222.

Ragothaman, A. \& Anderson, W.A. (2017). Air quality impacts of petroleum refining and petrochemical industries. Environments - MDPI, 4(3), 1-16.

Sheng, Q. \& Zhu, Z. (2019). Effects of nitrogen dioxide on biochemical responses in 41 garden plants. Plants, 8(2), 1-15.

Shubbar, R. (2019). Numerical simulation of air pollutants using CALPUFF model at an urban area in Baghdad-Iraq (unpublished $\mathrm{PhD}$ thesis). Pukyong National University, Busan.

Shubbar, R.M., Suadi, A.J. \& Al-Jiboori, M.H. (2018). Study the concentration of $\mathrm{SO}_{2}$ emitted from Daura refinery by using screen view model. Al-Mustansiriyah Journal of Science, 29(3), 7-15. 
Vallero, D. (2014). Fundamentals of air pollution. Amsterdam: Elsevier

Wang, F., Chambers, S.D., Zhang, Z., Williams, A.G., Deng, X., Zhang, H., Lonati, G., Crawford, J., Griffiths, A.D., Ianniello, A. \& Allegrini, I. (2016). Quantifying stability influences on air pollution in Lanzhou, China, using a radon-based "stability monitor": Seasonality and extreme events. Atmospheric Environment, 145, 376-391.

Weber, E. (1982). Fundamentals for the application of a Gaussian Plume Model. In E. Weber (eds.), Air Pollution: Assessment Methodology and Modeling (pp. 101-128). Berlin: Springer.

Zhao, X., Li, K., Xiao, D. \& Li, X. (2019). Experimental study of the mechanism of acid rain-gabbro Interaction. E3S Web of Conferences, 98, 01053. https://doi.org/10.1051/ e3sconf/20199801053

\section{Summary}

Estimating gaseous pollutants in the air near Daura Refinery, Daura Power Plant and South of Baghdad Power Plant by calculating the fuel discharge. This study addresses estimation of emission rates and concentrations of $\mathrm{SO}_{2}, \mathrm{CO}$ and $\mathrm{NO}_{2}$ gases emitted from Daura Refinery (DR), Daura Power Plant (DPP) and South of Baghdad Power Plant (SBPP) by calculating the fuel discharge. The estimations were made by using the Gaussian plume model of dispersion at distances within $10 \mathrm{~km}$ from the pollution source for January, April, July and October 2017 under two stability conditions, slightly stable and moderately unstable. The effect of wind speed and direction as well as the ambient temperature of the surrounding air on the dispersion and transmission of air pollutants were also investigated. It was found that the unstable conditions are better for dispersing out atmospheric pollutants. The results showed that Zafarania District was the most affected by pollutants emitted from DR and BSPP while Daura District was more affected by DPP due to the prevailing wind direction. It was also found that an increase in wind speed leads to a decrease in the concentration of pollutants. The concentration of pollutants is inversely proportional to the height of the chimney, the speed of the gas leaving the chimney, while it is directly proportional to the diameter of the chimney. DPP has higher emission rates than DR and SBPP while at the surface level, the pollutants concentrations emitted from DR are greater than those emitted from DPP and SBPP.

\section{Authors' address:}

Thaer O. Roomi - corresponding author (https://orcid.org/0000-0002-5764-5075) Adel S. Abed (https://orcid.org/0000-0001-5175-904X) Mustansiriyah University

College of Science

Department of Atmospheric Science

Palestine Street, 46131 Baghdad

Iraq

e-mail: th.roomi.atmsc@uomustansiriyah.edu.iq a.adelsaad96@gmail.com 